the annotation of the letters $\mathbf{4 5}$ and following dealing with the corn eelworm (Anguina tritici, Nematode) where it is not taken into consideration that there was at that time a confusion between two diseases of corn: the ergot produced by a fungus, Claviceps purpurea and the corn-cockle caused by $A$. tritici, above mentioned. When Saussure mentions to Bonnet Fontana's observations on 'les anguillules de l'ergot', he has evidently in mind the corn eelworm and not $C$. purpurea; therefore the eggs described are indeed those of the Nematode and not the spores of the fungus as Castellani writes wrongly in his footnotes p. 281. A short glance at the historical part of Davaine's monograph on the corn eelworm (Recherches sur l'anguillule du blé niellé, 1856) would have avoided this error. The editor is also wrong when he interprets (p. 279) the observations of Roffredi on $A$. tritici as concerning the fungus Puccinia graminis and the work of Fontana which he quotes in relation to the 'anguilles' (eelworms) is not Osservazioni sopra la rugine del grano (Lucca, 1767) but Saggio di osservazioni sopra il falso ergot e tremella (Firenze, 1775).

Last but not least, in the indexes closing the volume (pp. 557-66) it would have been much more convenient to give the numbers of the pages than of the letters which run sometimes on ten or more pages.

\title{
J. THÉODORIDĖS
}

Glass and British Pharmacy 1600-1900: a Survey, and Guide to the Wellcome Collection of British Glass, by J. K. CReLLIN and J. R. ScotT, London, Wellcome Institute

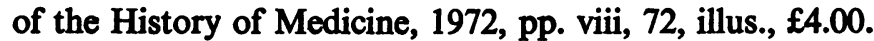

This important catalogue by Crellin and Scott giving details of colours, shapes and dimensions of some 1,200 examples of specie jars, carboys, storage and display jars, presents a serious study of apothecary and pharmacy vessels during the four hundred years to 1900 . It is the second in the Catalogue series promised by Dr. F. N. L. Poynter, Director of the Wellcome Institute, when Dr. Crellin's Medical Ceramics appeared in 1969. The period now covered is one in which the art and practice of the apothecary, successor to the medieval spicer, became the provenance of the chemist and druggist of the eighteenth century and the pharmacist a century later.

From the introduction and the informative notes the reader will appreciate the extent of the search made by the authors of any literature bearing upon the whole subject of pharmaceutical equipment, some part of which has already been published in Medical History, 1969, 13, 51-67 (Drug Weighing) and 1970, 14, 132-53 (Fluid Medicines, etc.). When did the first show carboys, those large display vessels that used to designate the pharmacy, come into use? Their forerunners, the clear storage vessels and the later coloured ones with floral designs, all illustrated, indicate the pharmacy owner's pride in his possessions-function and ornament were happily blended. How to date these vessels and how to decide when one kind of label, painted, etched or recessed, replaced another? Where were the shelf containers, the shop rounds, made? These and so much else are being discarded because of lack of space now that their usefulness is over. Some guidance in dating comes from examining trade cards, billheads and old trade catalogues, but when shapes, designs and labels continued for half a century the problem is not an easy one, though the present-day collector would like to have everything defined for him. 


\section{Book Reviews}

The way in which the descriptions of objects are linked with the illustrations, furnished by the resources of the Wellcome Institute and the skill of its photographer, makes for ready reference. The Catalogue represents what is in the Wellcome Collection and though amplified by the notes is not held out as a complete guide to all the pharmaceutical glassware of the period though there cannot be much that has eluded the vigilant eyes of the authors. The briefest reference is made to the laboratory equipment used by the small-scale preparer of chemicals and galenicals which, well into the end of the period reviewed, was operated in the back premises of the enterprising chemist and druggist before the era of the manufacturing chemist and wholesaler furnished him with what he needed at no trouble to himself. It may be that this is intended in order to leave the field clear for a separate monograph on chemical glass in which the Wellcome Collection is rich.

The authors by their systematic study have made a most useful addition to the Wellcome Catalogue series and have maintained the high standard now accepted as consonant with publications of the Wellcome Institute.

LESLIE G. MATTHEWS

Die Geschichte der Arzneimittelforschung, by B. IsSEKUTZ, translated into German by Adam Farago, Budapest, Akademiai Kaido, 1971, pp. 651 [no price stated].

Bela Issekutz, Emeritus Professor of Pharmacology, has, over a long period, collected a large number of references pertaining to the discovery of new medicinal agents and their introduction into therapy. The information is presented in this book which is so packed with names, dates and references that it must be considered a valuable contribution to the reference literature on the history of modern therapy. Its value to the historian, however, rests more on the facts and references it contains than to narrative or interpretation. The introductory section on the history of therapy and pharmacology is short, sketchy and limited in scope. The remainder of the work is divided up in the manner of a modern textbook on clinical pharmacology. The thirty-four chapters are each devoted to a distinct pharmacological group, e.g. analgesics, anticonvulsants, heavy metals, ganglion-blocking agents and anti-carcinogens. Each discovery is discussed in chronological order and related to discoveries and developments in the same branch of pharmacological and therapeutic knowledge. This method of presentation is useful for reference purposes but tends to obscure the significance of an individual piece of research in relation to the total development of modern therapy. It also squeezes out or reduces to a mere passing reference studies which, although they do not fit any of the pharmacological categories, nevertheless had a significant influence on the progress of the science, e.g. Magendie and Delille's experiments with arrow poisons in 1809.

Each section ends with a comprehensive list of references. These lists are impressive and for that reason the reader is warned that there are some gaps. In the section on hypnotics Liebreich's study of chloral is discussed but his 1869 paper on the subject does not appear in the list of references. There is no reference to the work of T. C. Butler who showed that chloral is reduced to trichlorethanol-a conclusion which led to the discovery of the narcotic tribromoethanol. In the literature on curare reference is made to eighteenth-century experiments by C. M. de la Condamine and 